\title{
Towards on the conservation of rare species Iris glaucescens (Iridaceae) in Novosibirsk oblast: ecoinformative multimodal analysis of the area
}

\author{
Konstantin Baikov ${ }^{1,2 *}$, and Vladimir Doronkin ${ }^{1}$ \\ ${ }^{1}$ Central Siberian Botanical Garden of the Siberian Branch of the Russian Academy of Sciences \\ (CSBG SB RAS), 630090 Novosibirsk, Russia \\ ${ }^{2}$ Novosibirsk State University, 630090 Novosibirsk, Russia
}

\begin{abstract}
Multimodal ecoinformation analysis as an modern computative approach to geospatial investigation of biodiversity structure is performed on maximum entropy method for local populations of Iris glaucescens rare species of vascular plants that is included in Red Book of Novosibirsk Oblast. The most informative environmental variables were ranged and examined in detail. According to obtained results, trio of the most important variables in the scale of 1/12 arc-degree (5.0 arc-minutes) global model, includes: 1) maximum average diurnal tempreature of surface air in the warmest period of an year (bio5) $-32.7 \%$, annual mean temperature of surface air (bio1) - 11.2\%, and maximum average diurnal tempreature of surface air in July $(\operatorname{tmax} 7)-9.0 \%$. Three of the most important variables in the scale of $1 / 60$ arc-degree (1.0 arc-minutes) regional model (Zone 18) are: maximum average diurnal tempreature of surface air in the warmest period of a year (bio5) $-35.7 \%$, maximum average diurnal tempreature of surface air in Juny (tmax6) - 23.1\%, minimum average diurnal tempreature of surface air in October $(\operatorname{tmin} 10)-7,7 \%$. Therefore, climatic variables that influense on the amount of heat in the warmest period of a year, may be taken into account as factors, limiting population size of $I$. glaucescens.
\end{abstract}

\section{Introduction}

Modelling of an geospatial pattern for any chosen biological taxa is the actual task in rational nature using and bioresources saving, because for effective conservation of any rare and endangered species we need at first to see in what climatic conditions the it prefers to live, and what are its specific requirements for survival, its ecological niche [1,2].

Iris glaucescens Bunge is the rare species of vascular plants included in the Red List of the Novosibirsk region.

According to the published data $[3,4]$, the climatic factors limiting the number of populations of this species on territories of Novosibirsk oblast are not defined still.

* Corresponding author: kbaikov2018@mail.ru 
The purpose of this scientific research is the ecoinformative multimodal assessment of the general (total) environmental situation in the area of Iris glaucescens in Novosibirsk Oblast, with determination the set of the most influential climatic variables limiting its distribution on this territory, and quantitative analysis of variables position in climatic spectra.

To achieve this goal, the following tasks were set: 1) build global and regional models of an area of the species in different scales; 2) develop the protocol for assessing the level of favorable environmental conditions in and around the locality; 3) build climate spectra for each obtained model; 4) range the most influential climate variables and quantify them in different models; 5) determine the factors limiting the distribution of the species on the territory of Novosibirsk region.

\section{Material and methods}

Data on this species locations on the territory of Novosibirsk Oblast are received from the published sources [3,4] and verified with the scientific collection and bioresources database of Central Siberian Botanical Garden, Siberian Branch of Russian Academy of Science «Herbarium of vascular plants, lichens and fungi (NS, NSK)», available at the address http://herb.csbg.nsc.ru:8081/. Herbarium specimens were tested in according to the stable combination of diagnostic features for Iris glaucescens: crescently curvatued external leaves, slightly leaf venation and the thicked rhizome covered with the split remains of leaves [5]. This combination of diagnostic characters makes exactly distinguishing this species from closely related Iris ludwigii [6].

The study was performed for four local populations: 1) the vicinity of Nadyr swamp in Karasuk district of Novosibirsk Oblast (specimen NS0027297), with coordinates 077.60E, $53.49 \mathrm{~N} ; 2$ ) the vicinity of Astrodym village in Karasuk district of Novosibirsk Oblast [3, 4], with coordinates $077.76 \mathrm{E}, 53.65 \mathrm{~N}$; 3) the vicinity of Rasskasovo in Karasuk district of Novosibirsk Oblast [3,4], with coordinates $077.95 \mathrm{E}, 53.66 \mathrm{~N}$; 4) the vicinity of Erestnaya village in Ordynskoe district of Novosibirsk Oblast [3, 4], with coordinates 082.09E, 54.34N.

Probablistic models for the distribution of the species in Novosibirsk Oblast are constructed on climate layers imported from WorldClim, an international database of world climate, available at http://www.worldclim.org. Climatic layers in WorldClim are generated on the direct measurements of near 60000 meteostations through all the world [7], and only stations with a full range of observations of at least 30 years were selected. In the study, climatic data for 1970-2000 years were taken, including the period of Iris glaucescens registration. According to experimental data and their expert assessment, the most informative models can be constructed with complete set of all available climatic variables. We have excluded from regional modelling only altitude indicator which not climatic factor, but can significantly change the spathial pattern of a model. Simuration was run in MAXENT computer program based on maximum entropy method [8].

\section{Results}

In the global model of 1/12 arc-degree resolution (near 50,76 sq. km per a cell), the top 10 of the most informormative factors is, in decrease order (Table): (1) maximum average diurnal temperature of surface air in the warmest period of an year (bio5) $-32.7 \%$; (2) annual average temperature of surface air (bio1) - 11.2\%; (3) maximum average diurnal tempreature of surface air in July $(\operatorname{tmax} 7)-9.0 \%$; (4) minimum average diurnal tempreature of surface air in October $(\operatorname{tmin} 10)-7.7 \%$; (5) maximum average diurnal 
tempreature of surface air in June (tmax6) - 5.9\%; (6) maximum average diurnal tempreature of surface air in April (tmax4) - 5.3\%; (7) minimum average diurnal tempreature of surface air in February $(\operatorname{tmin} 2)-4.8 \%$; $(8)$ maximum average diurnal tempreature of surface air in August (tmax 8$)-4.0 \%$; (9) average monthly temperature of surface air in October (tmean10) - 3.9\%; and (10) maximum average diurnal tempreature of surface air in October $(\operatorname{tmax} 10)-3.0 \%$. Other factors have input less than $3.0 \%$.

Table. The most informative variables in the global and the regional climatic spectra for the area of Iris glaucescens in Novosibirsk Oblast

\begin{tabular}{|c|c|c|c|c|c|}
\hline $\begin{array}{c}\text { Spathial scale } \\
\text { degree) }\end{array}$ & $1 / 12$ & $1 / 12$ & $1 / 60$ & $\begin{array}{c}\text { Jackknife } \\
1 / 60\end{array}$ & $\begin{array}{c}\text { Average } \\
\text { rank }\end{array}$ \\
\hline \multicolumn{7}{|c|}{ Climatic variables and its ranks } \\
\hline bio5 / bio5_18 & 1 & 1 & 1 & $1-2$ & 1,125 \\
\hline bio1 / bio1_18 & 2 & 3 & 4 & 4 & 3,25 \\
\hline tmax7 / tmax7_18 & 3 & 2 & $(15)$ & $1-2$ & 5,375 \\
\hline tmin10 / tmin10_18 & 4 & - & 3 & 6 & - \\
\hline tmax6 / tmax6_18 & 5 & - & 2 & 3 & - \\
\hline tmax4 / tmax4_18 & 6 & - & 10 & - & - \\
\hline tmin2 / tmin2_18 & 7 & 4 & $(14)$ & - & - \\
\hline tmax8 / tmax8_18 & 8 & - & $(20)$ & 5 & - \\
\hline tmean10 / tmean10_18 & 9 & 7 & - & $8-9$ & - \\
\hline tmax10 / tmax10_18 & 10 & - & - & - & - \\
\hline tmin1 / tmin1_18 & $(13)$ & 5 & $7-8$ & - & - \\
\hline bio6 / bio6_18 & $(11)$ & 6 & - & - & - \\
\hline tmean12 / tmean12_18 & $(24)$ & - & 5 & - & - \\
\hline tmean4 / tmean4_18 & $(16)$ & 8 & 9 & $8-9$ & - \\
\hline tmin5 / tmin5_18 & - & 9 & - & - & - \\
\hline tmin9 / tmin9_18 & - & 10 & - & - & - \\
\hline tmin4 / tmin4_18 & - & - & $7-8$ & 7 & - \\
\hline bio3 / bio3_18 & $(23)$ & - & - & 10 & - \\
\hline tmax1 / tmax1_18 & - & - & 6 & - & - \\
\hline
\end{tabular}

Jackknife test on the world level produces the other top 10 of the climatic spectrum, in decrease order (see Table): (1) maximum average diurnal tempreature of surface air in the warmest period of an year (bio5) - near 4.0 points RTG (regularized training gain) of total 7.181 , (2) maximum average diurnal temperature of surface air in July (tmax7) - 3.7; (3) average annual temperature of surface air (bio1) - 2.6; (4) minimum average diurnal temperature of surface air in February $(\operatorname{tmin} 2)-2.5$; $(5)$ minimum average diurnal temperature of surface air in January (tmin1) - some less than 2.5 ; (6) minimum average diurnal temperature of surface air in coldest period of a year (bio6) - 2.3; (7) average monthly temperature of surface air in October (tmean10) - 2.1; (8) average monthly temperature of surface air in April (tmean4) - 1.9; (9) minimum average diurnal 
temperature of surface air in May (tmin5) - 1.8; and (10) minimum average diurnal temperature of surface air in September $(\operatorname{tmin} 9)-1.7$. Other factors have input less than 1.7 points of RTG.

In the regional model (climatic claster Zone 18) of 1/60 arc-degree resolution (near $2,026 \mathrm{sq}$. km per a cell), we get the next climatic spectre of influense variables, in decrease order (see Table): (1) maximum average diurnal temperature of surface air in the warmest period of a year (bio5_18) - 35.7\%; (2) maximum average diurnal temperature of surface air in June (tmax6_18) - 23.1\%; (3) minimum average diurnal temperature of surface air in October (tmin10_18) - 7.7\%; (4) average annual temperature of surface air (bio1_18) $7.4 \%$; (5) average monthly temperature of surface air in December (tmean12_18) - 5.2\%; (6) maximum average diurnal temperature of surface air in January (tmax 1_18) - 2.8\%; (78) minimum average diurnal temperature of surface air in April (tmin4_18) - 2.8\%; (7-8) minimum average diurnal temperature of surface air in January (tmin1_18) - 2.7\%; (9) average monthly temperature of surface air in April (tmean4_18) - 2.6\%; and (10) maximum average diurnal temperature of surface air in April (tmax4_18) - 1.9\%. Other variables have input less than $1.6 \%$.

Jackknife test on the region level produces the next climatic spectrum, in decrease order (see Table): (1-2) maximum average diurnal tempreature of surface air in the warmest period of an year (bio5_18) and maximum average diurnal temperature of surface air in Jule (tmax7_18) - nearly 2.0 points RTG (regularized training gain) of total 3.374; (3) maximum average diurnal temperature of surface air in June (tmax6_18) - 1.3; (4) average annual temperature of surface air (bio1_18) - nearly 1.2 ; (5) maximum average diurnal tempreature of surface air in August $\left(\overline{t m a x} 8 \_18\right)-1.0$; (6) minimum average diurnal tempreature of surface air in October $\left(\operatorname{tmin} 10 \_18\right)-0.9$; $(7)$ minimum average diurnal temperature of surface air in April (tmin4_18) - 0.8; (8-9) average monthly temperature of surface air in April (tmean4_18) - 0.7; (8-9) average monthly temperature of surface air in October (tmean10_18) $-0 . \overline{7}$; and (10) isotermality as a ratio of average diurnal range to temperature annual range (bio3_18) - 0.6. Other factors have input less than 0.6 points of RTG.

\section{Discussion}

Comparative analysis of two obtained spectra, at the global and regional levels, showed that maximum average diurnal temperature of surface air in the warmest period of an year is the most informative climatic variables in both cases: $35,7 \%$ of the total input in the regional model and $32,7 \%$ of the total input in the world model. The warmest period of an year consists of June, July, and August in the southern parts of the territory of Novosibirsk Oblast, and July is the most important among them. Leading role of maximum average diurnal temperature of surface air in the warmest period of an year is confirmed of results in both Jackknife tests (see Table), but on the regional level maximum average diurnal temperature of surface air in July has the same high value. As a result, the value of average rank for the factor bio5/bio5_18 calculated by four climatic spectra is 1,125 .

Maximum average diurnal temperature of surface air in July (tmax7 / tmax7_18) has shared the 1-2 rank with bio5_18 in Jackknife test of a regional level, has 2th position in Jackknife test of a global level, 3 th rank in the climatic spectrum of global level, and only 15 th position in the climatic spectrum of regional level. As a result, the value of average rank for the factor tmax $7 / \operatorname{tmax} 7 \_18$ calculated by four climatic spectra is 5,375 .

Position of average annual temperature of surface air (bio1/bio1_18) show high stability in all four spectra: 2th in global model, 3th in Jackknife test of a global level, 4th in regional model and Jackknife test on a regional level. Of stability, this factor is like to 
bio5 / bio5_18. The value of average rank for the factor bio1/tmax1_18 calculated by four climatic spectra is 3,25, significantly higher than of $\operatorname{tmax} 7 / \operatorname{tmax} 718$.

Only three variables (bio5, bio1, and tmax7) have place in the top 10 of investigated spectra, some other important factors can be there three times or only twice. Maximum average diurnal temperature of surface air in June (tmax6/ tmax6_17) has the best position among them: 2th place in the regional model, 3th - in Jackknife test on a regional level, and 5 th rank in the global model. The closest competitor is minimum average diurnal temperature of surface air in October ( $\left.\operatorname{tmin} 10 / \operatorname{tmin} 10 \_18\right)$ having 3th rank in the regional model and 4th rank in the global modal, and 6th position in Jackknife test of a regional level.

Therefore, climatic variables that influense on the amount of heat in the warmest period of a year, namely maximum average diurnal temperature of surface air in the warmest period of an year (bio5 / bio5_18), maximum average diurnal temperature of surface air in July (tmax7 / tmax7_18) and in June (tmax6 / tmax6_18), may be taken into account as key factors, limiting population size of rare species $I$. glaucescens in the territory of Novosibirsk Oblast. The total input of three these variables is $59.6 \%$ in the regional model and $47.6 \%$ in the global model. The obtained results do not confirm the opinion of environmental experts that distribution of vascular plants in the steppe zone of Northern Asia is limited by the amount of precipitation. The total contribution of the variables determining the amount of precipitation is only $1.5 \%$ in the regional model (exclusively the variable bio15_18 - precipitation seasonality) and only $0.2 \%$ in the global model (exclusively the variable prec6 - amount of precipitation in June) of the distribution for $I$. glaucescens.

This work was performed within the framework of the state assignment of the CSBG SB RAS, on the topic AAAA-A17-117012610055-3. The methodical part of the experimental studies is supported by the grant of Novosibirsk State University (Russia) «Creation and development of the Laboratory for biogeomodeling and ecoinformatics of Faculty for Natural Sciences NSU» under the TOP-100 program. In preparing the publication, the scientific collection and bioresources database of Central Siberian Botanical Garden, Siberian Branch of Russian Academy of Science «Herbarium of vascular plants, lichens and fungi (NS, NSK)» USU 440537 were used.

\section{References}

1. G.E. Hutchinson, Cold Spring Harbor Symposia on Quantitative Biology 22, 415-427 (1957)

2. I. Yu. Koropachinsky, Arboriflora Sibiri (GEO, Novosibirsk, 2016)

3. A.A. Krasnikov, Iris glaucescens, in Krasnaya kniga Novosoborskoi oblasti (ARTA, Novosibirsk, 2008)

4. A.A. Krasnikov, Iris glaucescens, in Krasnaya kniga Novosoborskoi oblasti (Novosibirsk, 2018)

5. V.M. Doronkin, Iridaceae, in Flora Sibiri, Araceae - Orchidaceae (Nauka, Novosibirsk, 1987)

6. V.M. Doronkin, A.N. Kupriyanov, A.L. Ebel, Bot Zh, 95, 1726-1736 (2010)

7. S. Fick, R. Hijmans, Int J Climatol, 37, $4302-4315$ (2017)

8. S.J. Phillips, M. Dudik, R.E. Schapire, ICML '04, 655-662 (2004) 